\title{
Educational Faculty Members' Perceptions on Multicultural Teacher
}

\author{
Rafet Günay ${ }^{1} \&$ Dolgun Aslan ${ }^{2}$ \\ ${ }^{1}$ Faculty of Education, Yildiz Technical University, Istanbul, Turkey \\ ${ }^{2}$ Minitry of National Education, Istanbul, Turkey \\ Correspondence: Rafet Günay, Faculty of Education, Curriculum and Instruction, Yildiz Technical University, \\ Istanbul, Turkey. Tel: 90-50-7238-2206. E-mail: gunay.rafet@gmail.com
}

Received: January 27, 2016

Accepted: March 1, 2016

Online Published: March 15, 2016

doi:10.5539/jel.v5n2p136

URL: http://dx.doi.org/10.5539/jel.v5n2p136

\begin{abstract}
This purpose of this study is to determine how the perceptions of teaching personnel members were conceptualized through use of metaphorical images with regard to the multicultural teacher. In this study, a phenomenological design, a type of qualitative research design was used. A total of 323 teaching personnel members employed at 71 educational faculties in Turkey participated voluntarily in the study. The data of the participants were analyzed using descriptive content analysis. The metaphors most used by the teaching personnel members were those of conductor, treasure chest of knowledge, Rumi, a restaurant chef, a gardener, a rainbow, a democrat, a prism and a guide. Whether one compares the Department of Educational Sciences with other departments or makes a comparison of the main subject areas within the Department of Educational Sciences, of all the themes produced, the perception seems to be shared that the multicultural teacher is able to synthesize the viewpoints of different cultures. These appeared to be no misunderstandings or misconceptions regarding the concept of the multicultural teacher with no distinction recorded between the Department of Educational Sciences and the main subject areas.
\end{abstract}

Keywords: educational faculty, multicultural education, metaphor, phenomenogical research, Turkey

\section{Introduction}

The population imbalances that have occurred due to the uncontrolled increase in migration that has taken place in the early part of the 21 st Century has had a tangible effect on the development of education systems all over the world. This rapid cultural change has led to the emergence of a new type of education that encompasses different types of attitudes, beliefs and behaviors. Multicultural education, one of the new types of educational system, is described in the academic literature as a form of educational process that rejects traditional approaches and that encourages encourages changes as part of its nature. By refusing to discriminate between students on grounds of language, religion or gender and by incorporating cultural pluralism into the learning and teaching process while simultaneously fostering mutual cultural respect and contributing positively to students' cognitive and ethical development, degrees of diversity are emphasized and in such a fashion, the process ensures that an increase in academic success is realized (Banks, 2008; Campbell, 1999; Gunay \& Aydin, 2015).

According to Banks (2008), multicultural education advocates the following targets at the core of its phlosophy: (i) to help students better understand themselves by looking at events and people from different cultural perspectives, (ii) to provide cultural, ethnic and linguistic options to students, (iii) to assist students in adopting knowledge, skills and attitudes which will help them to better establish communication both within the dominant group of the culture and in their interaction with those from other ethnic cultures, (iv) to reduce descrimination and anxiety experienced by certain groups on account of specific racial, physical or cultural characteristics, (v) to help students to acquire literacy and numeracy skills that will offer them the opportunity in an ever-increasingly technological environment and in an increasingly globalized and "single" world, to allow them professionally to compete with students who have obtained their education in different countries. Within the context of these goals and targets, it is necessary to support the acquisition of skills and abilities that will take students to the furthest point possible. In this context, expressions such as "melting pot" and "salad bowl" have been employed with respect to the specific situation of Turkey with regard to multicultural education. This is on account of the fact that Turkey, that can be considered the cradle of civilizations, is a geographical region encompassing a rich cultural diversity and a rich social composition (Aydin, 2013; Kaya, 2015). It is a country that within this unique 
geography incorporates a wide variety of elements that contribute to an overall picture that is extremely heterogenuous in nature.

With this in mind, it is necessary to make wide-ranging preparations with regard to devising a ready to employ methodology within the learning and teaching process that takes into account the needs, expectations, thinking styles and strategies of the individual learner. Within such a methadology, "cultural diversity and difference" need to be brought to the forefront of the planning process. Also, in this context, there is a need to work with experienced institutions who are knowledgeable on the topic of multiculturalism (Gunay, 2014). The key points of contact in this regard in finding solutions with regard to multicultural education are the faculties of education. Teaching personnel responsible for the training of future teachers need to undertake the necessary efforts to address the problems at hand (Karatas \& Oral, 2015). The views and reflections of teaching personnel on this issue may exert a (positive) influence on the system. There is an absence of content and techniques with regard to multicultural education in programs at both higher education and at other levels of the educational system in Turkey. In fact, this contradicts the actual situation with regard to Turkey as a country that encompasses a number of different ethnic groups and structures. Multicultural education as put forward in the Tyler model may be considered an alternative educational program that may be constructed in accordance with the requirements of that society (Aydin, 2012; Faltis, 2014).

Throughout history, Anatolia prevailed as a center for many civilizations. Accordingly, multiculturalism was a reality in this geographical region since the emergence dominance of ancient civilizations. Anatolia welcomed many different cultures for many centuries. It is possible to see the traces of those cultures, indicating how people used to generally get along in those periods. The different groups involved in Turkey demand such a right from time to time. Turkey is structured around 36 different ethnic cultures. Therefore, it is a clear mistake to take this social structure into consideration as population variability (Gunay \& Aydin, 2015).

In this study, the concept of the multicultural teacher was examined from the point of view of teaching personnel employed at Educational Faculties, and a deepening of the understanding of the subject was realized through the use of metaphorical images. For this reason, it is necessary to take into consideration the concept of the metaphor. Lakoff and Johnson (2005) described the metaphor as a "process of discovery". As can be seen, metaphors serve to reveal or bring out our viewpoints with regard to a particular fact or phenomenon, and aid us in acquiring a deeper understanding of the underlying reasons for such a perspective. There is therefore an attempt in this study to examine the perceptions with regards to the concept of the multi-cultural teacher and the underlying reasons or causes for such perceptions and viewpoints.

In academic literature on the topic of education there has been an increase in the number of studies on the topic of metaphors, particularly over recent years both domestically (in Turkey) and internationally. The titles of some of these studies are as follows: "Teacher" (Gunay, 2015), "Education" (Gunay, Aydin, \& Damgaci, 2015; Gunay \& Yucel-Toy, 2015), "Learning" (Uiba, Kikas, \& Tropp, 2011), "The Student" (Saban, 2010), "The School" (Hadar, 2009), "Educational Program(s)" (Gultekin, 2013) and "Knowledge" (Saban, 2008). Nevertheless, on scanning recent academic literature on the topic (of metaphors), there appear to have been no studies conducted on subject of "the multicultural teacher". Because, a multicultural education teacher looks more details when she/he try to solve global problems (Aydin \& Tonbuloglu, 2014). In addition, a multicultural teacher can provide a suitable learning and positive classroom environment for all students who come from different cultural background. Furthermore, in none of the studies carried out with regard to the concept of the teacher have data been collected concerning teaching personnel at a higher educational level. In this regard, it is thought that the study regarding the analysis of metaphorical images held and created by teaching personnel in the higher education sector will make an important contribution to the educational system in Turkey that encompasses such a varied social structure.

Moreover, the fact that a large number of students from abroad have embarked on study at an international level in Turkey, has led teaching personnel to review programs so as to render them more suitable within this new context of increased intercultural interaction. In particular over the course of the past few years, the forced migration of large groups of people of all ages and educational levels, most notably from Syria to Turkey, has necessitated the taking of a number of measures and precautions with view to their integration. Cultural adaptation, education and accomodation have become key issues on the national agenda of Turkey in recent times. For reasons such as those listed above, it is thought that this study, that takes cultural diversity as its focal point, may prove helpful in assisting teaching personnel to deliver lessons in a more active and communicative manner. This study, by making use of metaphors provided by and concerning teaching personnel and the effectiveness and productivity of the lessons that they are involved in, may serve to make important 
contributions that may bring about solutions and progress with regard to problems experienced in the field of multicultural education. In other words, the attitudes developed with regard to the multicultural teacher may be revealed through formal and informal observations of teaching personnel responsible for the training of teaching candidates teachers and by drawing on their experiences in the field. Great care is required in researching this situation. In this regard, the aim of this study, is to determine how the perceptions of teaching personnel members were conceptualized through use of metaphorical images. The aim of the study in this context was to find answers to the following questions.

1) What are the metaphorical images that teaching personnel have with regard to the multicultural teacher?

2) Which common themes or subjects headings can these metaphorical images be grouped under with regard to their common properties or characteristics?

(1) What were the differences and similarities between the Educational Sciences Department and other departments with regard in the themes that were created concerning the mutlicultural teacher?

(2) What similarities differences are demonstrated between the (teaching personnel) of the principal subject areas within the Department of Educational Sciences?

\section{Methods}

\subsection{Research Design}

In this study, a phenomenological design, a type of qualitative research design was used. The phenomenon or main focus of the study was defined as the concept of the multicultural teacher. In this design, experience is accumulated and acquired in a detailed and careful fashion regarding how phenomena are perceived, how they are described, how they are perceived, discussed and how these assume meaning (Creswell, 2012; Merriam, 2013).

\subsection{Participants}

In this study, a purposeful sampling method was employed. On account of the fact that the e-mail addresses of certain teaching personnel may be exchangeable or that mail addresses may not be easily accessible, a purposeful sampling method was used. In order to collect the data obtained, all educational personnel employed at all Educational Faculties in Turkey during the spring term of the 2014-2015 academic year were sent an e-mail message informing them about the research study. As a result, a total of 323 teaching personnel members employed at 71 educational faculties in Turkey participated voluntarily in the study. As regards the gender breakdown, $152(47 \%)$ of the participants were male while $171(53 \%)$ were female. When the participants are considered in terms of their ages, $12(4 \%)$ were between 20 and 25 years of age, $69(21 \%)$ were between 25 and $30,52(16 \%)$ between 30 and 35, $57(18 \%)$ between 35 and 40, $52(16 \%)$ between 40 and 45, $33(10 \%)$ between 45 and 50, $30(9 \%)$ between 50 and 55 and $18(6 \%)$ above 56 years of age. The other demographic data/information not included above are provided in Table 1.

Table 1. The demographic characteristics of teaching personal participating in the study

\begin{tabular}{lcclcc}
\hline Moderating Factors & $f$ & $\%$ & Moderating Factors & $f$ & $\%$ \\
\hline Length of Service (in years) & & & Educational Level & & \\
$0-5$ & 75 & 23 & Technical College & 3 & 1 \\
$6-10$ & 50 & 15 & Pre-Bachelors Degree & 2 & 1 \\
$11-15$ & 62 & 19 & Bachelors Degree & 20 & 6 \\
$16-20$ & 52 & 16 & Masters Degree & 75 & 23 \\
$21-25$ & 33 & 10 & Doctorate & 223 & 69 \\
$26-30$ & 27 & 8 & Department & & \\
$31-35$ & 12 & 4 & Educational Sciences & 108 & 334 \\
$36+$ & 12 & 4 & Foreign Languages Education & 45 & 13.9 \\
Title & & & Primary & 56 & 17.3 \\
Research Assistant & 84 & 26 & Computer and Teaching Technologies Education & 23 & 7.1 \\
Teaching Assistant & 39 & 13 & Education for Mathematics and Science at & 36 & 11.1 \\
\hline
\end{tabular}




\begin{tabular}{lcclcc}
\hline & & & Secondary Level & \\
$\begin{array}{l}\text { Doctoral Archival Faculty } \\
\text { Member }\end{array}$ & 12 & 4 & Humanities for Secondary Level & 18 & 5.5 \\
Assistant Professor & 106 & 33 & Special Education & 6 & 1.8 \\
Associate Professor & 55 & 17 & Turkish Language Education & 9 & 2.8 \\
Full Professor & 27 & 8 & Physical Education and Sports Teaching & 7 & 2.2 \\
& & & Fine Arts Education & 13 & 4.0 \\
& & & Religious Education and Morals/Ethics Education & 2 & 0.6 \\
\hline
\end{tabular}

On study of Table 1, it can be seen that teaching personnel with between 0 and 5 years of service participated in the study. Furthermore, among those who participated in the study, $84(26 \%)$ had the title of Research Assistant, 39 (13\%) Teaching Assistant, 12 (4\%) that of Doctor, 106 (33\%) that of Assistant Professor, 55 (17\%) of Associate Professor and 27 (8\%) held the title of Full Professor. Moreover, a large number of those who participated in the study consisted of peronnel members who had completed doctoral studies. $(69 \%)$ When considered from the point of view of departments involved, personnel from the Department of Educational Department had the highest rates of participation (33.4\%). This figure was followed by the Primary Education Department with $17.3 \%$ and the Foreign Languages Education Department with 13.9\%.

\subsection{Data Collection}

So as to reveal the metaphors held by teachers with regard to the concept of the multicultural teacher, all teaching personnel members participating in the research study were asked to complete the following sentence: "a multicultural teacher resembles a ... because...". With this aim in mind, all participants were sent a form on which they were expected to supply details regarding their gender, age, field of study, length of service, title, educational level and the sentence "a multicultural teacher resembles a ... because...". The participants were asked to share their thoughts by using this sentence and by using the concept of a metaphor. By allowing space after the word "because", the teaching personnel were requested to define their reasons for the metaphors they had expressed. The teaching personnel members participating in the study then were sent a metaphor form developed by the researchers via an online environment (docs.google.com) and the information was saved online in such a way that only the researcher could access and see it. The e-mail addresses pf the teaching personnel, were accessible via mail addresses that were used on the same public university website. Furthermore, the views of four experts in the field (of multicultural education), and three experts in the field of assessment and evaluation were elicited for the purposes of the preparation of the metaphor form. The views of the experts were evaluated and it was established that reliability was achieved at a rate of $100 \%$.

\subsection{Data Analysis}

The responses of the participants were analyzed using descriptive content analysis. Content analysis is a method of gathering and analyzing textual content (Silverman, 2013). In the study under discussion, the analysis of the metaphors supplied/created by the participants was carried out in three stages.

\subsubsection{The Tabulation of Data}

The metaphors were arranged in alphabetical order, and the answers given by teaching personnel members were encoded. The metaphors were then arranged according to the reasons of preference and the opinion of the participant that best represented the particular metaphor was then chosen as the example metaphor. The answers given by each participant were then collected with respect to the content of the forms, participants were given a sequence number and the data was collected under the following headings: age, department, length of service, title, level of education and the sentence: the raw data were then checked a second time by the other researcher, with the metaphors submitted by the teaching personnel arranged according to gender, age, field of study, service, title and level of education.

\subsubsection{Development of the Codes and Themes}

At this stage, embarking from the metaphors elicited, seven themes or topic headings were cretaed from the point of view of the common characteristics of the metaphors with regard to the characteristics of the multicultural teacher. The common metaphors were then grouped under these seven themes. First of all, the metaphors were arranged in alphabetical order and the metaphorical concepts produced by the teaching personnel were analyzed from the perspective of their common characteristics. The metaphors that were examined with regard to the 
features of the multicultural teacher, were then assigned a specific code (name) (for example: equal and impartial, cultural awareness, universality, harmony, far from prejudice, individual differences, pedagogy). Later, these codes were transformed into themes or topic headings that were able to express the qualities of the multi-cultural teacher. Some examples of these categories were: a teacher who synthesizes fuses the viewpoints of different cultures, the enlightening and dedicated teacher.

\subsubsection{Ensuring Validity and Reliability}

In qualititative research studies, the submission of reports outlining in detail the data compiled and providing an explantion of how the researcher arrived at results represents an important criterion of evaluation (Glesne, 2013; Merriam, 2013). For this reason, the results of the study were explained in detail and the metaphors obtained were compiled and arranged in keeping with this aim. Processing and interpretation of the findings were conducted taking into account the charateristics of the themes produced. To ensure reliability, care was taken to reach a concensus of four people, including the researcher at each stage of the study (choice of design, creation of quations, collection and analysis of data and interpretsyion of thr results). Furthermore, the opinions of experts (six teacher trainers employed at the Departments of Educational Sciences at Yildiz Technical University and Marmara University) were elicited to determine whether the metaphors under the topic headings themes were correct. In this regard, the list of themes was given to a total of six faculty members. The faculty members were then asked to submit their critical feedback regarding the themes headings on the list and the order of the metaphors. As a result of the comparison of the mapping of the metaphors and theme headings, an agreement was regarding regarding the internal reliability of the data collection and this was employed as the final version for the study.

\section{Findings}

In this section, space is allocated to discussion of the general findings obtained from the study. At a later stage, the themes headings that emerged as a result of the metaphors created by teaching personnel were presented and space was provided for inclusion of quotations emanating from the answeres provided by teaching personnel. At the end of the metaphors and expanations mentioned above, the sequence number given to the teacher during data entry as well as their gender and title was included between parantheses. For example, an entry was coded as follows (69, $\mathrm{M}$, AAP). In the codification, "M" and "F" were used to indicate the gender of the participant. Furthermore, the titles of the teaching personnel were also included in the codification. According to the codification: " $\mathrm{A}$ " = Research Assistant, "T" = Teaching Assistant, "D" = Doktor, "AAP" = Associate Assistant Professor, "AP" = Assistant Professor and "FP" = "Full Professor".

\subsection{Metaphors Produced Regarding the Concept of the Multicultural Teacher}

The teaching personnel members, produced a total of 66 metaphors with regard to the concept of the multicultural teacher. From the metaphors produced by all teachers, those occupying the top ten positions can be ordered as follows: (1) Conductor of an Orchestra $29(\% 8,98)$, (2) Treasure Chest of Knowledge, $25(\% 7,74)(3)$ Rumi 20 (\%6,19), (4) A Cook $16(\% 4,95)$, (5) A Gardener $15(\% 4,64),(6)$ A rainbow $15(\% 4,64)$, (7) A Democrat1 $1(\% 3,41),(8)$ A pine tree $10(\% 3,10),(9)$ A prism $10(\% 3,10),(10)$ A guide $10(\% 3,10)$. The number of participants who produced the metaphors that occupied the top ten rankings was $161(\mathrm{n}=161)$; this represented half of the total group.

\subsection{Themes and Topic Headings Generated from the Metaphors Regarding the Multicultural Teacher}

The multicultural teacher is the person who, taking the principles of multicultutal education and the different ethnic groups present in the society in which he lives into account responsible into account, is responsible for the preparation of an environment that will foster comprimise, respect and cultural plurality Expressed in basic terms, the multicultural teacher embodies the features of multicultural education. According to Nieto and Bode (2013) the characteristics of multicultural education are those that make up a process and critical pedagogy including: an opposition to racism, basic education, and most importantly an education that is accessible for all students, a comprehensive education and social education. Culturally possessing a heterogeneous structure, Turkey had to take into consideration all language, culture and religious demands in the field of education pertaining to different groups presently residing in Turkey (Gunay \& Aydin, 2015). Gorski (2010) mentions some of the benefits of multicultural society and these include: (i) presentation to the class (ii) subject content, (iii) educational comprehensiveness, (iv) social responsibility and responsibility as a citizen.

In this context, this information helped in enlightening certain aspects of the study and in the creation of the topics included. In the study at hand, the themes generated by teaching personnel members with regard to the multicultural teacher are shown in Figure 1. 


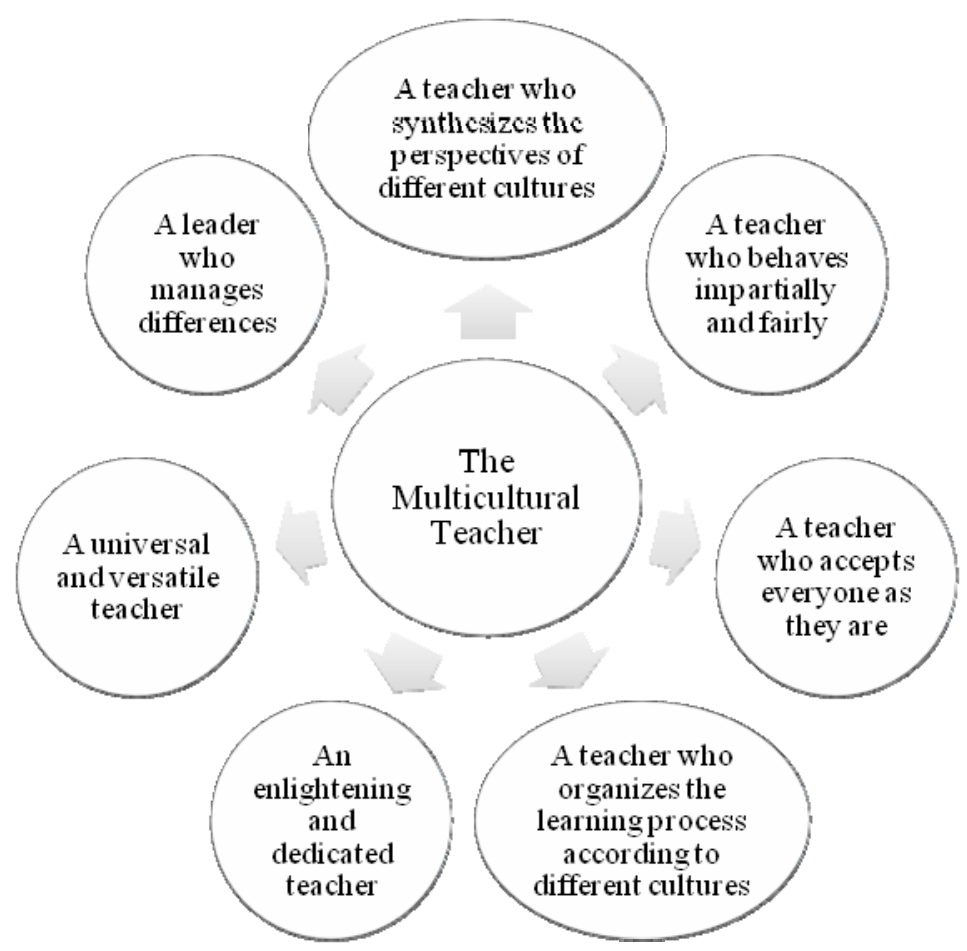

Figure 1. Themes with regard to the multicultural teacher

From the themes created from the metaphorical images held by teaching personnel members with regard to the concept multicultural teacher, "a teacher who synthesizes/merges the viewpoints of different cultures $(\mathrm{n}=137)$ " was the most, "an enlightened and dedicated teacher" was the second $(\mathrm{n}=48)$ and "a teacher who accepts everyone as they are $(\mathrm{n}=35)$ " was the third most generated theme/topic. The least generated themes were "a universal and versatile teacher $(\mathrm{n}=26)$ " and "a teacher who behaves in a impartially and fairly $(\mathrm{n}=22)$ ". The Distribution of Metaphors according to themes are shown in Table 2.

Table 2. The distribution of metaphors according to themes

\begin{tabular}{cccc}
\hline Categories & $f$ & Metaphors of the Multicultural Teachers & $f$ \\
$n=7$ & $\%$ & $\%$ \\
\hline
\end{tabular}

An octopus, a mother, a bee, a cook, ashure (Noah pudding), a mirror, a gardener, a treasure chest of knowledge, a computer, a

A teacher who synthesizgs the viewpoints of different cultures $\% 42,41$ well, a world map, the world, a factory, a rainbow, the sky, the scientist, a chameleon, a modern educator, a pine tree, a garden of flowers, a farmer, a jetty, a democrat, the sea, a bottomless sun, a prizm, a pomegranate, a conductor, a forest, freedom, a guide, an artist, a performer, a sponge, a singer, a mechanic, a peacock, a technical director (football coach), a tailor, a stage, earth, salt, an expert, the rain

A mother,a bee, a cook, a mirror, a gardener, a treasure chest of

An enlightened and $\quad 48$ dedicated teacher $\% 14,86$ knowledge, a palette of colours, a cloud, a pine tree, a democrat, the world, a rainbow, the sun, a courtroom, Rumi, a musician, a conductor, the forest, earth, an expert, the rain A key, a bee, Ashure (Noah soup), a gardener, a composer,

A teacher who accepts everyone as they are
$(\% 34,85)$ courtroom, Rumi, musician, a conductor, a guide, a performer, a 


\begin{tabular}{|c|c|c|c|}
\hline & & song & \\
\hline $\begin{array}{l}\text { A leader who } \\
\text { manages } \\
\text { differences }\end{array}$ & $\begin{array}{c}28 \\
\% 8,67\end{array}$ & $\begin{array}{l}\text { A key, a cook, a mirror, a gardener, a treasure chest of } \\
\text { knowledge, a pine tree, a democrat, the sea, the sun, a prizm, the } \\
\text { internet, a ladle, a candle, a pomegranate, the internet, a ladle, a } \\
\text { candle, a pomegranate, a conductor, a guide, earth/soil, rain, a } \\
\text { father without authority }\end{array}$ & $\begin{array}{c}19 \\
(\% 28,79)\end{array}$ \\
\hline $\begin{array}{l}\text { A teacher who } \\
\text { organizes the } \\
\text { learning process } \\
\text { according to } \\
\text { different cultures }\end{array}$ & $\begin{array}{c}27 \\
\% 8,36\end{array}$ & $\begin{array}{l}\text { A mother, a cook, a mirror, a treasure chest of knowledge, a } \\
\text { garden of flowers, a farmer, a democrat, the sea, the world, a } \\
\text { film archive, a rainbow, a prizm, a drug, the internet, a carpet } \\
\text { weaver, Rumi, an artist, litmus paper, salt }\end{array}$ & $\begin{array}{c}20 \\
(\% 30,30)\end{array}$ \\
\hline $\begin{array}{l}\text { A universal and } \\
\text { versatile teacher }\end{array}$ & $\begin{array}{c}26 \\
\% 8,05\end{array}$ & $\begin{array}{l}\text { A mother, a treasure chest of knowledge, a computer, a } \\
\text { chameleon, a fridge, a pine tree, a mountain, a democrat, the } \\
\text { sun, a cat, Rumi, a musician, a conductor, a performer, earth }\end{array}$ & $\begin{array}{c}17 \\
(\% 25,76)\end{array}$ \\
\hline $\begin{array}{l}\text { A teacher who } \\
\text { behaves in an } \\
\text { impartially and } \\
\text { justly manner }\end{array}$ & $\begin{array}{c}22 \\
\% 6,81\end{array}$ & $\begin{array}{l}\text { An octopus, a key, a cook, Ashure (Noah gpudding) a treasure } \\
\text { chest of knowledge, a scientist, a world map, a rainbow, a } \\
\text { prizm, a cat, Rumi, a pomegranate, an artist, an umbrella, a } \\
\text { peacock, the rain }\end{array}$ & $\begin{array}{c}17 \\
(\% 25,76)\end{array}$ \\
\hline
\end{tabular}

* The categories are listed from those with the highest to those with the lowest frequency.

\subsection{Themes Generated}

\subsubsection{A Teacher Who Synthesizes Viewpoints}

For this theme 50 metaphors were obtained from 137 teaching personnel members. Above all considerations, the teacher should (in the eyes of the participants) possess knowledge and opinions on the subject he or she teachers Furthermore, the teacher should have accepted the differences in terms of the religions, languages, skin colours, denominations, ehnic groups, gender and sexual orientation of the students who have come together to make up his class, should not have attempted to change these aspects and reflected them as he or she encounters them. He or she should be seen to be a role model and make a pcontribution to the development of similarly positive attitudes and behaviours. The thoughts of some of the teaching participants are presented below:

...Creates a beautiful harmony from different voices. [254, M, AP]

...By uniting different cultures, we gain a satisfying viewpoint and vision that satisfies are hunger (as human beings). [257, F, AP]

...Shows all cultures and invites us to understand (them). [266, M, FP]

\subsubsection{An Enlightening and Dedicated Teacher}

For this theme 22 metaphors were received from 48 teaching personnel members. Teachers should have such an accumulation of knowledge that it reflects the differences present in his class in the most effective way, and he should be seen as a person who can offer assistance according to every student's needs. In this regard, the multicultural teacher is one who enlightens the more he throws light on a subject, in the same way as light that hits the surface of the Earth, serves to reveal its hidden attractive aspects. The views of some of the teaching personnel members in this regard were as follows:

...he has a lot of knowledge and enlightens students with this knowledge. [79, F, AAP]

...Hh reveals a number of riches that have forcibly been made to remain in the darkness. [56, F, FP]

...the sun does not make any distinction between race or language; it enlightens everyone. [240, M, FP]

\subsubsection{A Teacher Who Accepts Everybody as They Are}

This theme generated a total of 23 metaphors from 35 teaching personnel members. On this topic, the teacher accepts the students without looking at the students' personal characteristics and without making any discrimination. Whoever that person he enocunters may be, he does not close the door to them. He is pictured as a teacher who does not establish "absolute" authority. Taking cultural differences into account, the teacher shows respect for the individuality of the person in front of him and demonstrated tolerance towards him. He accepts all 
the characteristics of the other person and displays a suitable behaviour towards him. The thoughts of some of the teaching personnel members on this topic are presented below.

...he does not establish dominance while helping the student to construct his own existence. [61, M, D]

...he gives an education that accepts everybody's culture. [217, M, AAP]

“...he approaches differences with tolerance”. [32, M, FP]

\subsubsection{A Leader Who Manages Differences}

With regard to this theme, 19 metaphors were created from the responses of 28 teaching personnel members. According to the teaching personnel members, the multicultural teacher is seen as a visionary who, in an environment where there are many different understandings, voices and types of information, directs the class like a conductor of an orchestra, creating a harmony as he does so by bringing all differences into a single symphony, leading the class on the road to new projects that they will create together. The thoughts of some of the teaching personnel in this regard are found below:

...He has to work closely with people from many different cultures. He needs great endeavour to manage so many differences. [248, M, FP]

...He knows how more than one instrument may be played together simultaneously and in the end, how to ensure a fantastic work of music emerges in the end. [41, F, AAP]

3.3.5 A Teacher Who Organizes the Learning Process According to Different Cultures

For this theme 20 metaphors were generated from 27 teaching personnel members. The multicultural teacher, in the context of this theme, is able to provide an educational environment that allows for class members to accustom themselves to other cultures, encourages respect towards the values of those from other cultures, facilitates harmony with and acceptance of the existence of competing cultures and serves to eradicate prejudices in this regard. There is an attempt to apply a program that blends the educational and teaching processes with the knowledge, culture and skills accumulation of all cultures. The views of some of the teaching personnel members are listed below:

“...ensures that the understanding that no culture is superior to another does not just remain empty words, but rather within the class in terms of learning, communication and relationships sets down a civilized foundation for education" [126, M, AAP]

"...like a restaurant chef, he wants every vegetable to interact with one another... In one sense, the teacher must prepare the environment, and must allow students to undergo different experieneces." [160, F, AAP]

3.3.6 The Universal and Versatile Teacher

With regard to this theme/topic, 17 metaphors were created from 26 teaching personnel members. According to the teaching personnel members, the teacher perceives and interprests the world and his immediate environment in a universal manner. The multicultural teacher must be able to interpret the conditions of today's world effectively, to create common areas in which children from different cultures may be brought together and be equipped with the tools to address the points of interest and needs of every child. Some of the teaching personnel members expressed their views on the subject as follows:

World citizens do not look for uniformity. [287, M, AAP]

...Because he is aware of the existence of different lands and seas.. He collects these within his being. [152, M, FP]

Within himself, he encompasses all countries, cultures, languages and languages and offers them a home/Place to stay. [127, F, AP]

\subsubsection{A Teacher Who Behaves in an Impartial and Just Manner}

With regard to this theme 17 metaphors were generated from 22 teaching personnel members. The teaching personnel members were of the view that the multicultural teacher should "rise in the skies" of all the students in the class and without discrimination according to factors such as language, ethnic origin, colour, or religion should enlighten their lives behaving in a generousi impartial and just manner. Some teaching personnel members expressed their views as follows:

...he shares knowledge without discriminating. He possesses knowledge that can benefit everyone. [93, $F, A A P]$ 
...he tells all students to approach him without discrimination. [31, M, FP]

...in a true sense, the teacher remains objective. [235, F, D]

3.3.8 The Similarities and Differences in Themes and Topics with Regard to the Multicultural Teacher

The themes and topics that were created from the opinions of the teaching personnel members were then compared according to the departments of the teaching personnel members. The results of the comparison of the themes produced by teaching personnel memebers is given in Table 3 .

Table 3. A Comparison of the themes generated between the department of educational sciences and other departments

\begin{tabular}{lcccc}
\hline & \multicolumn{3}{c}{$\begin{array}{c}\text { Educational } \\
\text { Sciences }\end{array}$} & \multicolumn{3}{c}{ Other } \\
& $f$ & $\%$ & $f$ & $\%$ \\
\hline A teachertments & \\
An enlightening and self-sacrificing teacher & 45 & 40.18 & 92 & 43.60 \\
A teacher who accepts everybody as they are & 21 & 18.75 & 27 & 12.80 \\
A leader who manages differences & 15 & 13.39 & 20 & 9.48 \\
A teacher who organizes the learning process according to different & 7 & 6.25 & 21 & 9.95 \\
cultures & 8 & 7.14 & 19 & 9.00 \\
A universal and versatile teacher & 9 & 8.04 & 17 & 8.06 \\
A teacher who behaves in an impartially and fairly & 7 & 6.25 & 15 & 7.11 \\
\hline Total & 112 & 100.0 & 211 & 100.0 \\
\hline
\end{tabular}

According to the findings, the top two themes generated by teaching personnel members at both the Department of Educational Sciences and the other departments were the same. For both groups in first position was "a teacher who synthesizes the view points of different cultures" and in second position, "an enlightening and dedicated teacher". For the other themes/topics it was found that the ranking of the theme and the number of teaching personnel did differ. However, for both groups the theme "a teacher who behaves in an impartial and just manner" was placed in the final position.

\subsubsection{Differences between the Main (Subject) Areas of the Department of Educational Sciences}

Teaching personnel members are employed within the Department of Educational Sciences according to the main (subject) areas of the department (Table 4). The Department of Educational Sciences consists of the following main areas: Education Programs and Teaching (EPT), Educational Administration and Inspection (EAI), Psychological Counseling and Guidance (PCG), Educational Assessment and Evaluation (EAE), Educational Sociology (ES) and Educational Philosophy (EP). While the EPT department contains more educational personnel members than the other departments put together; nevertheless, similar results to other departments were recorded, with the exception of the theme "enlightening and dedicated teacher".

Table 4. A Comparison of the principal areas of the department of educational sciences with respect to the metaphors generated

\begin{tabular}{lcccccccccc}
\hline & \multicolumn{2}{c}{ EPT } & \multicolumn{2}{c}{ PCG } & \multicolumn{2}{c}{ EAI } & \multicolumn{2}{c}{ EAE } & \multicolumn{2}{c}{ Other } \\
& $f$ & $\%$ & $f$ & $\%$ & $f$ & $\%$ & $f$ & $\%$ & $f$ & $\%$ \\
\hline A teacher who merges/synthesizes the & 25 & 54.35 & 8 & 40.00 & 8 & 44.44 & 1 & 14.29 & 3 & 14.29 \\
viewpoints of different cultures & 3 & 6.52 & 2 & 10.00 & 1 & 5.56 & & & 15 & 71.43 \\
An enlightening and dedicated teacher & 6 & 13.04 & 5 & 25.00 & 1 & 5.56 & 3 & 42.86 & & \\
A teacher who accepts everybody as they are & 3 & 6.52 & & 4 & 22.22 & & & \\
A teacher who manages differences & & & & & & & & & &
\end{tabular}


A teacher who organizes the learning process according to different cultures

A universal and versatile teacher

A teacher who behaves impartially and fairly. Total

$\begin{array}{cccccccccc}5 & 10.87 & 1 & 5,00 & 1 & 5.56 & 1 & 14.29 & & \\ 1 & 2.17 & 2 & 10.00 & 3 & 16.67 & 2 & 28.57 & 1 & 4.76 \\ 3 & 6.52 & 2 & 10.00 & & & & & 2 & 9.52 \\ 46 & 100 & 20 & 100.0 & 18 & 100 & 7 & 100 & 21 & 100\end{array}$

Approximately three quarters of the teaching personnel members in the EPT and EAI deparments defined the multicultural teacher as "a teacher that synthesized the viewpoints of different cultures". On the other hand, there was more agreement from the other main department areas with the theme heading "an enlightening and dedicated teacher". However, The most prominent theme in the EAE department, while having a limited number of teaching personnel was that of "a teacher that accepts everybosy as they are".

\section{Conclusion, Discussion and Suggestions}

For the purposes of this study, the metaphors used to symbolize the multicultural teacher were collected under seven theme and headings. The metaphors most used by the teaching personnel members were those of conductor, treasure chest of knowledge, Rumi, a restaurant chef, a gardener, a rainbow, a democrat, a prism and a guide. In terms of educational title, assistant associate professors were the largest group that participated in the study. The reason for this may that the research topic attracted their interest, the wish to be included in the research as active members and the fact that the topic was of more relevance to them. Even if mainly teaching personnel from the Educational Sciences and Primary Teaching Departments took part in the study, teaching personnel from all departments played a role in helping realize the research.

The teaching personnel members responded positively to the theme created from their metaphors that the multicultural teacher was one who synthesized viewpoints from different cultures. By extension, they described the multicultural teacher as one who fused different cultures, brought different roles together, and whose qualities lay in creating connections between individuals, addressing every section of society, who knew how to behave towards those with different values and how one should comport oneself as a result. afterwards. Studies conducted by Banks (2008) and Aydin (2012), demonstrate that multicultural education is associated with the provision of education and teacher designed for different racial groups, and is based on an attempt to secure agreement of ideas between differnet groups and is based on development of cultural divsersity in societies in which numeorus racial groups are pressent. For this reason, it has been stressed by these researchers that the different ideas, traditions, behavior and lifestyles inherent in different cultures should be seen as a source of enrichment and need to be melted and merged in one large "cooking pot" so as to benefit everyone.

With regard to the theme of the enlightening and dedicated teacher, in the same way as light strikes the surface of the Earh and highlights all its inherent beautiful features, the teacher is seen by the participants in the study as one who runs to the help of everybody in his class with an inextinguishable energy and remains in conversation with those from every culture increasing the students knowledge and skills. This result reflects similar findings to those found in a study by Campbell (1999).

Those teaching personnel members who were in agreement with the theme heading that a multicultural teacher accepts everyone as they are, stated that the multicultural teacher should know the fine points of many cultures and have the ability to regard differences with tolerance. While the teacher, like the metaphor of the pine tree, does not bring anything from himself in light of the differences, it contributes great value to his personal and professional environment. The teacher needs to be respectful to every idea, accept people from every background and school of thought, and to be open to human values, and respectful to maintaining peace, balance and harmony and to the differences inherent in other people.

With regard to the theme heading that a multicultural teacher manages differences, the multicultural teacher was described as one who allowed the expression of every voice and who arranged the learning and traching process so that it created a harmonious atmosphere in which those individuals with different characetristics supported each other. In this context, the teacher was seen as someone who manages diversity, directs different groups within an environment of order and permits the expression of many voices while prevented chaos or confusion. According to Nieto and Bode (2013), teachers need to embrace the different languages, religions, ethnic backgrounds and values of all the students in the class and should act within a spirit of understanding; he should provide scope for activities which allow for socialization and integration (Phillion \& He, 2004). On this point, the responsibility falling to teaching personnel members, is to educate teacher trainees in such a way that they 
can address the students in their classes, all of whom have different qualities and characteristics, to increase their knowledge and experiences on this topic and to keep their horizons as wide as possible.

Concerning the theme that the multicultural teacher organizes the learning process in accordance with different cultures, the multicultural teacher should have information about every culture, should know that differences constitute a source of enrichment and that education should reflect this and furthermore be given in an objective and impartial way that does not pass judgement. Not pushing certain cultures to the forefront creates a postitive class environment. Furthermore, according to the teaching personnel members, a multicultural teacher may create an educational environment that renders students accustomed to other cultures, encourages them to respect the values of those people of other cultures, provides harmony by getting students to accept those from other cultures as they are and that serves to eradicate prejudices.

As regards the theme a multicultural teacher is universal and versatile, the teaching personnel members argued that the multicultural teacher was someone who was well-trained, experienced, reflected his acquaintance with various cultures and was able to host various cultures in his classrooms. He possesses a large amount of information that he shared with others and regarded every culture as a source of enrichment; in short, he could be regarded as a "world citizen". Furthermore, the multicultural teacher in this regard remains dedicated to improving himself and to following developments in his immediate environment so that a teacher ermerges who is versatile as regards his worldview, perception of the environment and interpretation.

As far as the theme of a teacher behaves impartially and fairly, the image of a teacher was drawn by teacher personnel members of someone who informed others in his environment without discrimination, is sensitive to inequalities in society, remains distant from false perceptions and prejudice, does not harshly reproach, recognizes the right of all those in class to express their views, who repells the negative energy present in society and who behaves in an equal way to everyone in class.

Moreover, the metaphors that emerged from the opinions given from teaching personnel members were compared with regard to which departments they were employed. First of all, there was an attempt to establish whether there were simalarities or differences between the Department of Educational Sciences and other sciences and then to discover whether there were similarities between the main areas of the Department of Educational Sciences. It is very important that those teachers who assume an active role within the educational system are given extensive training and equipped with the correct skills. In the current Turkish system of education, the role of teacher training is to a great extent given to Educational Faculties. The lessons that teachers receive and experiences they are exposed to while at educational faculties reflect the role of the teaching personnel that trained them. For this reason, teaching personnel members responsible for teacher training represented the principal focal point in this study. At faculties, it is expected that those teaching personnel members have competency as regards teacher training.

Debate still continues whether more weight should be attached to main area/topic lessons and subject knowledge or to vocationally-focused training lessons within teacher training (Yildirim, 2011). In particular, this is a discussion between teaching personnel responsible for vocational training lessons and main subject lesson teaching personnel; however, in the training system of today both types of teacher have responsibility fort he training of teachers, and this situation means that both groups are responsible for entering lessons with a training focus. For this reason, the themes emerging from those metaphors regarding the multicultural teacher generated by teaching personnel members at the Department of Educational Sciences were compared with those entering main subject lessons. Moreover, when the main subject areas were compared with one another the similarities were more striking. While the personnel members at the EPT, PCG and EAI emphasized the fact theme the multicultural teacher was able to synthesize the viewpoints of different cultures. It was noteworthy that those at the EAE gave prominence instead to the theme that the teacher accepted everyone as they were.

Whether one compares the Department of Educational Sciences with other departments or makes a comparison of the main subject areas within the Department of Educational Sciences, of all the themes produced, the perception seems to be shared that the multicultural teacher is able to synthesize the viewpoints of different cultures. This finding shows similarities with the results of studies conducted by Banks (2013), Sleeter and Grant (1994). According to Banks (2008), by giving value to cultural differences, there is the attempt to collect differences under one roof with multicultural education as its central principle so as to confirm the pluralism that teachers and citizens have contributed to the educational process.

Moreover, another aspect that needs to be focused on in this respect, that there appeared to be no misunderstandings or misconceptions regarding the concept of the multicultural teacher with no distinction recorded between the Department of Educational Sciences and the main subject areas. This situation raises the 
expectation further that those teaching personnel responsible for the training of teachers reflect multicultural aspects in their applications so as to equip the future teachers with skills and knoweldge with regard to the multicultural teacher. The fact that teaching personnel have been raised within the diversity and cultural richness of Turkey, and know how to behave when faced with some differences is a positive result of this study.

Another result that is worth paying attention to is the fact that there was almost no negative perception recorded with regard to the multicultual teacher. When one examines the themes on an individual basis the picture emerges that the teaching personnel have on the whole conveyed positive ideas regarding the multicultural teacher. In a study conducted by Gunay, Aydin and Damgaci (2015), that multicultural education needs to be placed by teaching personnel in safe hands, and if careful attention is not attached to its progress, it can lead to damage to the unity and integrity of the country.

In conclusion, teacher training in Turkey is known to be an area of education that is very expansive and that is generating a lot of effort and research. In order to address these perceived pressing definciencies, institutions and organizations with stake in the future of education such as the National Ministry of Education, the Higher Education Council, The Center for Student Selection and Placement and numerous civil society institutions together with organizations, teachers and experts and all others with a valid voice to bring to the topic, should work together to research and evaluate solutions and new policies. By examining the themes raised in this study and by examining results that may be suitable for future application in the Turkish education system. In this regard, only through the implementation of internationally recognized certificates and programs such as the Cambridge University Competency in Teaching Programme, The Certificate in English Language Teching and the Oxford University Masters Degree in Teaching can competent teachers be trained.

\section{References}

Aydin, H. (2012). Multicultural education curriculum development in Turkey. Mediterranean Journal of Social Sciences, 3(3), 277-287.

Aydin, H. (2013). A Literature-based Approaches on Multicultural Education. Anthropologist, 16(1-2), 31-44.

Aydin, H., \& Tonbuloglu, B. (2014). Graduate students perceptions on multicultural education: A qualitative case study. Eurasian Journal of Educational Research, 57, 29-50. http://dx.doi.org/10.14689/ejer.2014.57.3

Banks, J. A. (2008). An introduction to multicultural education (4th ed.). Boston: Allyn and Bacon.

Campbell, R. (1999). Pros and Cons of Multicultural Education. Retrieved September 20, 2015, from http://www.ehow.com/about_5147417_pros-cons-multicultural-education.html

Creswell, J. W. (2012). Research design: Qualitative, quantitative, and mixed methods approaches (4th ed.). United States: Pearson Education.

Faltis, C. (2014). Toward a race radical vision of bilingual education for kurdish users in Turkey: A commentary. Journal of Ethnic and Cultural Studies (EJECS), 1(1), 1-5.

Gorski, P. C. (2010). The challenge of defining multicultural education. Retrieved June 13, 2015, from $\mathrm{http}: / /$ www.edchange.org/multicultural/initial.html

Gultekin, M. (2013). The metaphors that primary education teacher candidates use regarding curriculum. Education and Science, 38(169), 126-141.

Gunay, R. (2014). Affirming diversity: The sociopolitical context of multicultural education. Journal of Ethnic and Cultural Studies (EJECS), 1(1), 43-44.

Gunay, R. (2015). Faculty of education members' perceptions on constructivist teacher. Elementary Education Online, 14(3), 845-861. http://dx.doi.org/10.17051/io.2015.51550

Gunay, R., \& Aydin, H. (2015). Inclinations in studies into multicultural education in Turkey: A content analysis study. Education and Science, 40(178), 1-21. http://dx.doi.org/10.15390/EB.2015.3294

Gunay, R., Aydin H., \& Damgaci, F. K. (2015). Metaphoric perceptions of faculty members' regarding multicultural education. Cankiri Karatekin University Journal of Institute of Social Sciences, 6(1), 291-312.

Gunay, R., \& Yucel-Toy, B. (2015). Metaphorical analysis of teacher trainers' conceptualization of constructivist education. International Online Journal of Educational Sciences, 7(4). http://dx.doi.org/10.15345/iojes.2015.04.005 
Hadar, L. (2009). Ideal versus school learning: Analyzing Israeli secondary school students' conceptions of learning. International Journal of Educational Research, 48, 1-11. http://dx.doi.org/10.1016/j.jijer.2009.01.002

Karatas, K., \& Oral, B. (2015). Teachers' Perceptions on Culturally Responsiveness in Education. Journal of Ethnic and Cultural Studies, 2(2), 47-57.

Kaya, Y. (2015). Teachers' Perceptions on Culturally Responsiveness in Education. Journal of Ethnic and Cultural Studies, 2(2), 33-46.

Lakoff, G., \& Johnson M. (2005). Metaphors We Live By (In G. Y., Demir, Tran. Ed.). Istanbul: Paradigma Publishing.

Merriam, S. B. (2013). Qualitative research: A guide to design and implementation (In S. Turan, Tran. Ed.). Ankara: Nobel Publishing.

Nieto, S., \& Bode, P. (2013). Affirming diversity: The sociopolitical context of multicultural education. Bask1. Boston, MA: Pearson Publication.

Phillion, J., \& He, M. F. (2004). Using life-based literary narratives in multicultural teacher education. Multicultural Perspectives, 6(3), 3-9. http://dx.doi.org/10.1207/s15327892mcp0603_2

Saban, A. (2008). Primary school teachers' and their students' mental images about the concept of knowledge. İlköğretim Online, 7(2), 421-455.

Saban, A. (2010). Prospective teachers' metaphorical conceptualizations of learner. Teaching and Teacher Education, 26(2), 290-305. http://dx.doi.org/10.1016/j.tate.2009.03.017

Silverman, D. (2013). Doing qualitative research (4th ed.). Thousand Oaks, CA: SAGE.

Sleeter, C., \& Grant, C. (1994). Making choices for multicultural education: Five approaches to race, class, and gender. New York, NY: Macmillan Press.

Uiba, K., Kikas, E., \& Tropp, K. (2011). Instructional approaches: Differences between kindergarten and primary school teachers. Compare: A Journal of Comparative and International Education, 41(1), 91-111. http://dx.doi.org/10.1080/03057925.2010.481121

Yildirim, A. (2011). Competing agendas and reform in teacher education. Uluslararası Eğitim Programları ve Öğretim Çalışmaları Dergisi, 1(1), 1-17.

\section{Copyrights}

Copyright for this article is retained by the author(s), with first publication rights granted to the journal.

This is an open-access article distributed under the terms and conditions of the Creative Commons Attribution license (http://creativecommons.org/licenses/by/3.0/). 